\title{
Base-catalyzed condensation of citral and acetone at low temperature using modified hydrotalcite catalysts
}

\author{
J.C.A.A. Roelofs, A.J. van Dillen, K.P. de Jong* \\ Department of Inorganic Chemistry and Catalysis, Debye Institute, Utrecht University, 3508 TB Utrecht, Netherlands
}

\begin{abstract}
A study on the catalytic properties of properly activated hydrotalcite (HT) with special attention to the nature and amount of active sites present in this solid base catalyst has been undertaken. Only a small fraction (5\%) of the available basic sites in the rehydrated calcined HT is active in liquid-phase aldol condensations. These sites exhibit high catalytic activity and are most likely localized at the edges of the HT-platelets. Besides a high activity, these modified HTs also show a high selectivity. No further condensation products other than diacetone alcohol (DAA) in the acetone self-condensation could be observed. Initial results with the citral-acetone condensation show that even at $273 \mathrm{~K}$ this reaction is catalyzed by modified HTs with a conversion of $65 \%$ and a selectivity of $90 \%$, when the citral concentration is not too high ( 1 wt. $\%)$. At higher citral concentrations, no reaction is observed indicating a negative order in citral concentration. () 2000 Elsevier Science B.V. All rights reserved.
\end{abstract}

Keywords: Hydrotalcite; Solid base catalysts; Citral; Basic sites; Aldol condensation

\section{Introduction}

In the fine chemical industry, a common method of coupling organic molecules via $\mathrm{C}-\mathrm{C}$ bond formation is the base-catalyzed aldol condensation. When executed in the liquid-phase, currently homogeneous alkaline bases are used as catalysts, which brings about large waste streams, while re-use of the catalyst is not practical. A key starting material for the commercial production of vitamin A (and of various carotenoids, flavors and fragrances) is pseudoionone (PS), which is synthesized by condensating citral and acetone (see Fig. 1a). Commercial citral is a mixture of two isomers due to the cis-trans isomerism at the $\mathrm{C}=\mathrm{C}$ bond near the aldehyde group. Besides the desired reaction, several side-reactions can take place too. Especially,

\footnotetext{
* Corresponding author. Fax: +31-30-2511027.

E-mail address: k.p.dejong@chem.uu.nl (K.P. de Jong)
}

self-condensations of citral and secondary reactions of PS are potential problems [1].

Some of these problems might be avoided using solid base catalysts. A promising candidate is hydrotalcite (HT), an anionic clay showing high activities and selectivities in these type of reactions [2,3]. The structure of $\mathrm{HT}, \mathrm{Mg}_{6} \mathrm{Al}_{2}(\mathrm{OH})_{16} \mathrm{CO}_{3} \cdot 4 \mathrm{H}_{2} \mathrm{O}$, resembles that of brucite, $\operatorname{Mg}(\mathrm{OH})_{2}$. In the latter structure, the magnesium cations are octahedrally coordinated by hydroxyl ions, resulting in stacks of edge-shared layers of the octahedra. In the HT structure, part of the $\mathrm{Mg}^{2+}$ ions are replaced by $\mathrm{Al}^{3+}$ ions resulting in positively charged layers, whose charge is compensated by interlayer anions, in the above case carbonate. Furthermore, water molecules are present in the interlayer [4-6]. To bring about catalytic activity in aldol condensation reactions, the HT has to undergo a specific treatment. For gas-phase condensation reactions at high temperature, calcination at $723-773 \mathrm{~K}$ is sufficient [7]. The 
a)<smiles>CC1=CCCC(C)=C1C=O</smiles>

citral

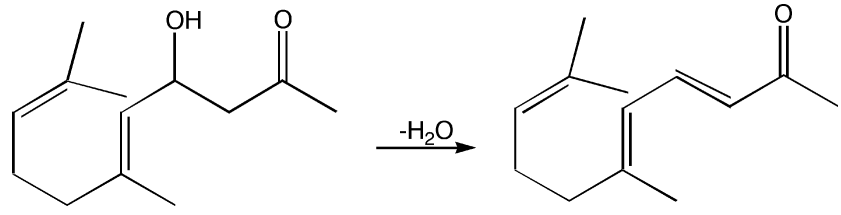

Pseudoionone
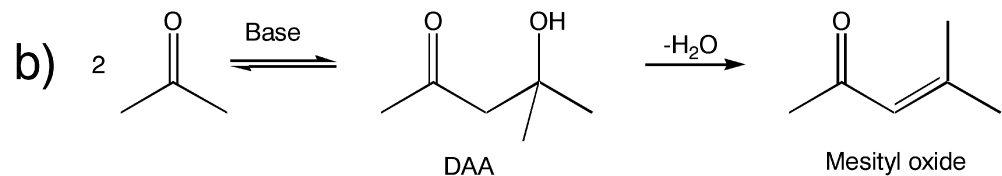

Fig. 1. (a) Base-catalyzed condensation of citral and acetone yielding PS after dehydration; (b) base-catalyzed self-condensation of acetone to DAA, followed by dehydration yielding MO.

resulting mixture of oxides exhibits strong Lewis basicity [8-11] capable of catalyzing various reactions like the self-condensation of acetone [12] and the condensation of formaldehyde and acetone [13]. However, these calcined samples are significantly less active and selective in liquid-phase condensations at lower temperatures $[14,15]$ due to, amongst others, the presence of Lewis acid sites [16]. To enhance the catalytic activity at these lower temperatures, the calcined samples have to be rehydrated at room temperature under exclusion of $\mathrm{CO}_{2}$, a treatment which results in the restoration of the original layered structure but now with $\mathrm{OH}^{-}$ions in the interlayer. This catalyst brings about, for instance, the condensation of benzaldehyde with acetone giving high yields and selectivities even at $273 \mathrm{~K}[3,15]$. Still, little is known about the nature and number of active Brönsted basic sites and the mechanism involved. A useful and relatively well described condensation reaction in the liquid-phase using rehydrated calcined HT is the self-condensation of acetone yielding diacetone alcohol (DAA) [14,17-19], shown in Fig. 1b. It may be concluded that a reaction temperature of $273 \mathrm{~K}$ is advantageous to prevent the dehydration of DAA to mesityl oxide (MO), and thus, to avoid the liberation of water which could influence the accessibility and the reactivity of the catalyst. Furthermore, the conversion of acetone to DAA is a reversible process and the equilibrium is favoring acetone with increasing temperatures [18].
Recently, Noda et al. [20] studied the production of PS at $330 \mathrm{~K}$ using a calcined HT. These authors concluded that at lower temperatures, the condensation of citral with acetone requires stronger basic sites than for the self-condensation of acetone and preferably has to be executed at higher temperatures. We concluded from their results that with a more suitably pretreated HT-catalyst better results, even at lower temperatures, are not to be excluded. In this study, we tested our catalyst in the citral-acetone condensation and the self-condensation of acetone at $273 \mathrm{~K}$ with special attention to the nature and number of active basic sites present in the HT-catalyst.

\section{Experimental}

\subsection{Preparation of the catalyst}

An aqueous solution ( $45 \mathrm{ml}$ ) of $0.1 \mathrm{~mol} \mathrm{Mg}\left(\mathrm{NO}_{3}\right)_{2}$. $6 \mathrm{H}_{2} \mathrm{O}$ and $0.05 \mathrm{~mol} \mathrm{Al}\left(\mathrm{NO}_{3}\right)_{3} \cdot 9 \mathrm{H}_{2} \mathrm{O}$ was added all at once to a second solution $(70 \mathrm{ml})$ containing $0.35 \mathrm{~mol}$ $\mathrm{NaOH}$ and $0.09 \mathrm{~mol} \mathrm{Na}_{2} \mathrm{CO}_{3}$ at $333 \mathrm{~K}$. The mixture was maintained at this temperature for $24 \mathrm{~h}$ under vigorous stirring, after which the white precipitate was filtered off and washed several times. Drying of the HT took place for an additional $24 \mathrm{~h}$ at $393 \mathrm{~K}$. ICP-analysis revealed an $\mathrm{Mg} / \mathrm{Al}$ ratio of $2 / 1$. Using this ratio and thermogravimetric analysis (TGA) results, 
the HT-structure $\left(\mathrm{Mg}_{6} \mathrm{Al}_{3}(\mathrm{OH})_{18}\left(\mathrm{CO}_{3}\right)_{1.5} \cdot 4 \mathrm{H}_{2} \mathrm{O}\right)$ was calculated.

After drying, the HT was heated in a nitrogen flow up to $723 \mathrm{~K}$ with a heating rate of $10 \mathrm{~K} / \mathrm{min}$ and kept at this temperature for $8 \mathrm{~h}$. Samples (typically $0.5 \mathrm{~g}$ ) were rehydrated at $303 \mathrm{~K}$ by use of a decarbonated water-saturated nitrogen flow of $100 \mathrm{ml} / \mathrm{min}$ for $48 \mathrm{~h}$. The rehydration procedure has been adapted from Rao et al. [3].

\subsection{Reaction procedures}

The self-condensation reaction of acetone was performed in a stirred double-walled cooled glass reactor, equipped with baffles. Typically, an amount of $2 \mathrm{~mol}$ acetone was cooled to $273 \mathrm{~K}$ and $0.3 \mathrm{~g}$ freshly prepared catalyst was added under a low flow of nitrogen to exclude atmospheric carbon dioxide. The amount of catalyst was varied in the range $0.2-0.8 \mathrm{~g}$ and this did not affect the results. Aliquots of $1 \mathrm{ml}$ were taken from the reaction mixture during the $24 \mathrm{~h}$ reaction period and analyzed using a Chrompack CP 9001 GC provided with a Chrompack CP 9050 autosampler. iso-Octane was used as internal standard to calculate the amount of DAA formed.

The procedure used for the citral-acetone condensation was similar to the procedure used with the self-condensation of acetone. The reaction mixture contained $1 \mathrm{wt} \%$ citral (Aldrich). Tetradecane was used as the internal standard. Product identification is complicated because of the facile dehydration reaction of the $\beta$-hydroxy-ketone (Fig. 1a) under the conditions needed for product analysis. To get around these problems, we decided to monitor the decrease of the citral concentration in time. In addition, no citral self-condensation was found to proceed while the amount of PS was monitored. The selectivity has been calculated by using both the $\beta$-hydroxy-ketone and PS signals from GC-analysis and comparing these with the amount of reacted citral.

\subsection{Catalyst characterization}

Powder X-ray diffaction (XRD) patterns were obtained by using an Enraf Nonius FR 590 with $\mathrm{Co} \mathrm{K} \alpha$ radiation. Thermal analyses with a heating rate of $6 \mathrm{~K} / \mathrm{min}$ were done on a Perkin Elmer TGS-2, equipped with a Fisons Instruments Thermo- lab quadrupole mass spectrometer. After outgassing under vacuum at $393 \mathrm{~K}$, a Micromeritics ASAP 2400 analyzer was used for $\mathrm{N}_{2}$-physisorption to determine surface areas and pore volumes.

$\mathrm{CO}_{2}$ adsorption measurements were performed at $273 \mathrm{~K}$ using a Micromeritics ASAP 2000. After calcination and/or rehydration as described above, the samples were quickly stored under nitrogen to avoid $\mathrm{CO}_{2}$-uptake from the atmosphere. Before measurements were performed, the samples were outgassed under vacuum at $393 \mathrm{~K}$.

\section{Results}

The XRD pattern of the synthesized HT compound exhibits the typical features of a HT (Fig. 2a). From the position of the 003 peak, the lattice distance of $7.8 \AA$ (corresponding to the sum of one cation layer and one interlayer distance) can be calculated [4]. By heating the samples up to $773 \mathrm{~K}$, the lattice structure is destroyed and a mixed oxide of the $\mathrm{Mg}(\mathrm{Al}) \mathrm{O}$ type is formed (Fig. 2b). Restoration of the original layered structure can be achieved to a large extent by rehydration of the calcined product at $303 \mathrm{~K}$ (Fig. 2c). In this last compound, the weak base $\mathrm{CO}_{3}{ }^{2-}$ (respectively, $\mathrm{HCO}_{3}{ }^{-}$) has been replaced by the strong Brönsted base $\mathrm{OH}^{-}$(via rehydration). The lattice distance is not affected by this replacement.

TGA and differential thermogravimetric analysis (DTG) results with the $\mathrm{HT}$ with $\mathrm{CO}_{3}{ }^{2-}$ as the compensating anion are shown in Fig. 3. The weight loss of HT-like compounds at increasing temperatures is well described in literature [10,21-23]. First, up to about $393 \mathrm{~K}$, adsorbed water is lost followed by interlayer water up to $540 \mathrm{~K}$. We ascribe the weight loss at higher temperatures (maximum between 640 and $720 \mathrm{~K}$ ) to dehydroxylation of the cation layers and the removal of carbonate via the formation of carbon dioxide. The monitored mass signals in terms of water and carbon dioxide confirm these findings (data not shown). There has been some discussion in the literature about the starting temperature of these processes. Kloprogge and Frost $[24,25]$ found that carbonate decomposition starts even at $343 \mathrm{~K}$. We are inclined to agree with these authors that it is possible for surface carbonate groups to decompose at these low temperatures but, in view of our own results, we are convinced that 


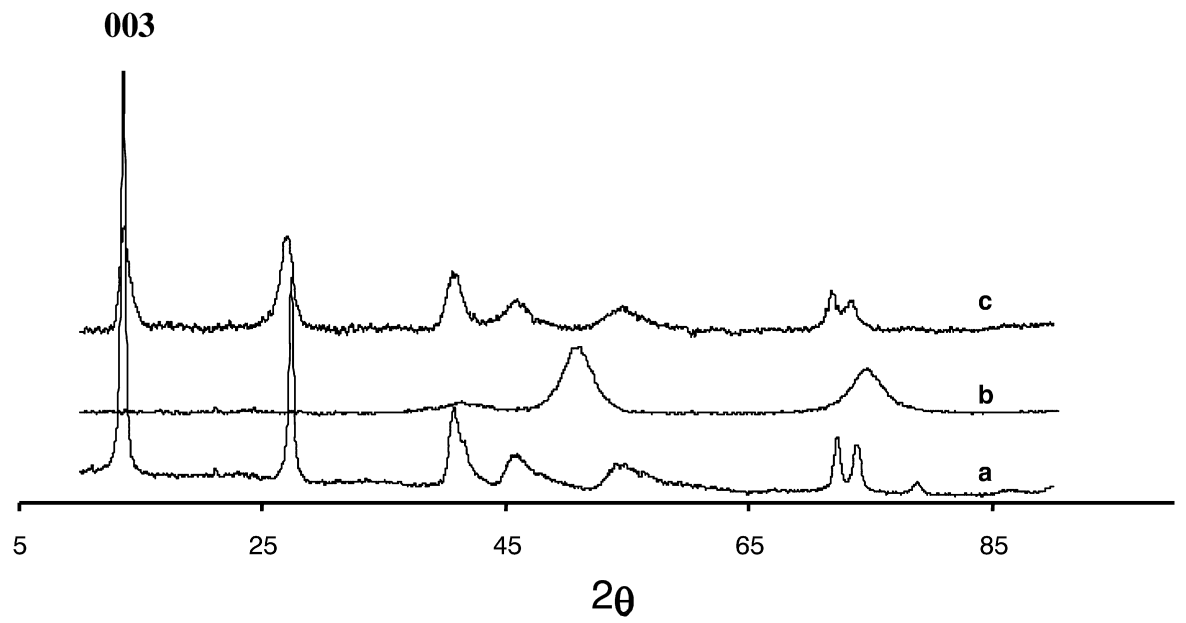

Fig. 2. XRD patterns of (a) HT as synthesized; (b) HT heated in $\mathrm{N}_{2}$ atmosphere at $723 \mathrm{~K}$; (c) HT after $48 \mathrm{~h}$ rehydration at $303 \mathrm{~K}$.

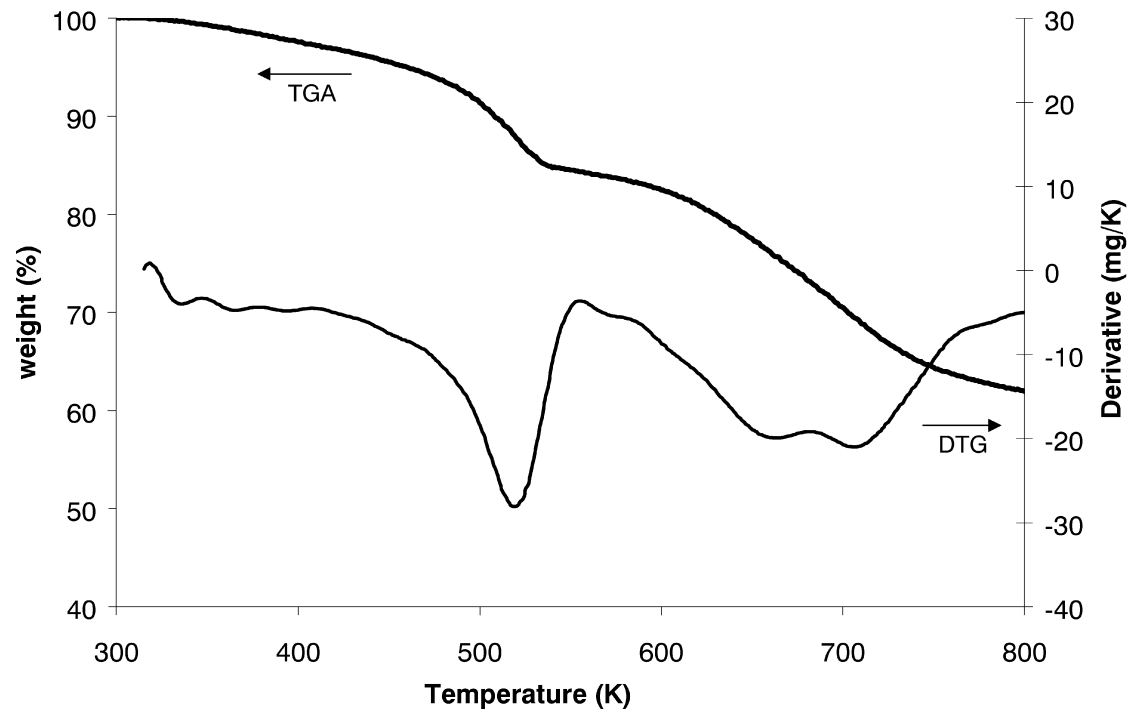

Fig. 3. TGA-DTG of HT as synthesized.

interlayer carbonate groups are stable at this low temperature. We ascribe evolution of $\mathrm{CO}_{2}$ above $673 \mathrm{~K}$ to the decomposition of intermediately formed $\mathrm{MgCO}_{3}$.

The results from our physisorption measurements are given in Table 1. Calcination results in a large increase in BET surface area from 88 to $253 \mathrm{~m}^{2} / \mathrm{g}$. This is partly due to the formation of micropores as well as mesopores as can be concluded from the large increase in total pore volume. The micropores vanish
Table 1

Results from $\mathrm{N}_{2}$-physisorption measurements

\begin{tabular}{lcll}
\hline & $\begin{array}{l}\text { BET surface } \\
\text { area }\left(\mathrm{m}^{2} / \mathrm{g}\right)\end{array}$ & $\begin{array}{l}\text { Micropore } \\
\text { volume }(\mathrm{ml} / \mathrm{g})\end{array}$ & $\begin{array}{l}\text { Total pore } \\
\text { volume }(\mathrm{ml} / \mathrm{g})\end{array}$ \\
\hline HT & 88 & Nil & 0.77 \\
HT calcined & 253 & 0.06 & 1.10 \\
HT rehydrated & 57 & Nil & 0.66 \\
\hline
\end{tabular}




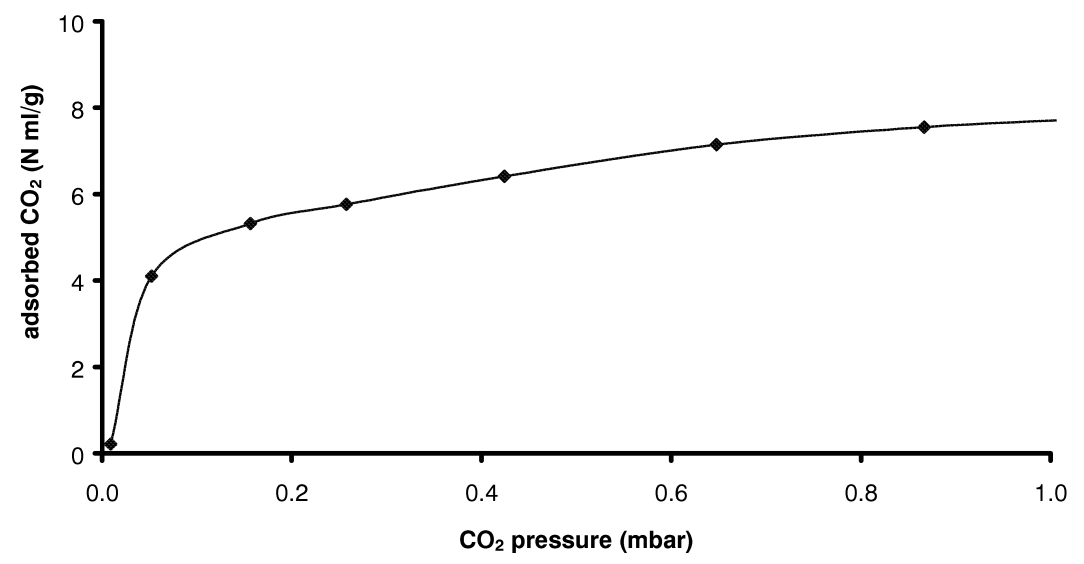

Fig. 4. Adsorption isotherm of $\mathrm{CO}_{2}$ on the modified $\mathrm{HT}$ at $273 \mathrm{~K}$.

during rehydration while the layered structure is restored resulting in a significant decrease of the BET surface area, from 253 to $57 \mathrm{~m}^{2} / \mathrm{g}$.

In order to estimate the total amount of accessible Brönsted basic sites present, $\mathrm{CO}_{2}$ adsorption measurements have been performed at low pressures. The results of such an experiment are shown in Fig. 4. Rao et al. [3] found a similar $\mathrm{CO}_{2}$-uptake at these low pressures. The total number of basic sites in the HT can be calculated from the number of $\mathrm{Al}^{3+}$-ions present as established by ICP analysis. This number is proportional to that of the compensating anions, $\mathrm{OH}^{-}$in case of the rehydrated HT. From the above results, we estimate that only $5 \%$ of the totally available basic sites participate in the condensation reactions, which indicates that the reaction most likely takes place at the edges of HT-platelets. Further work will concentrate on elucidation of this hypothesis by varying the platelet size and measuring of changes of the catalytic activity due to this variation.

We tested the catalytic activity of HT as synthesized, the calcined HT and the rehydrated calcined HT samples in the self-condensation of acetone. The results are shown in Fig. 5. The HT with carbonate as the compensating anion shows no significant activity. The calcined sample formed after heating in $\mathrm{N}_{2}$ exhibits an activity comparable to that of $\mathrm{MgO}[14,26]$. Its activity in the benzaldehyde-acetone condensation has been ascribed to strongly bound hydroxyl groups still present at the surface after calcination at $773 \mathrm{~K}$. The Lewis basic sites $\left(\mathrm{O}^{2-}\right)$ are not expected to cat-

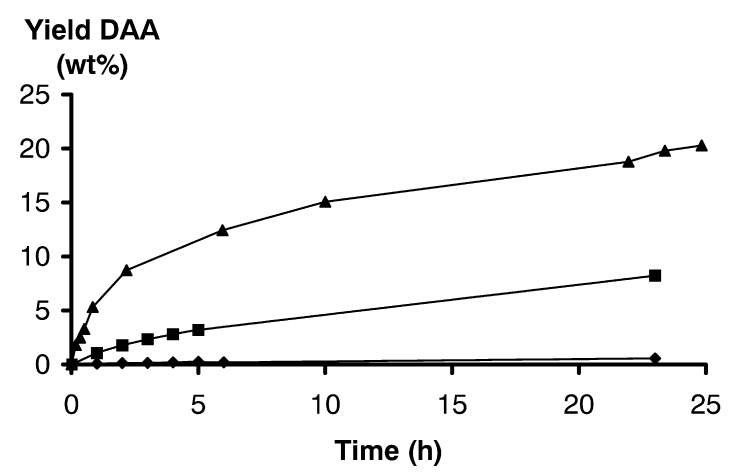

Fig. 5. DAA production with HT as synthesized $(\bullet)$, calcined HT ) and calcined/rehydrated HT ( $\mathbf{\Delta})$.

alyze this type of condensation reactions [15]. The rehydrated calcined HT-catalyst with $\mathrm{OH}^{-}$ions between the cation layers shows a high initial activity (Table 2). Even within $1 \mathrm{~h}$, the initial rate decreases due to the establishment of equilibrium at $273 \mathrm{~K}$ (23.1 wt.\% DAA

Table 2

Initial reaction rates and conversion levels after $24 \mathrm{~h}$ for acetone self-condensation at $273 \mathrm{~K}$ with the calcined/rehydrated HT catalyst

\begin{tabular}{lcc}
\hline & $\begin{array}{l}\text { Initial rate } \\
\left(\mathrm{g}_{\text {DAA }} \mathrm{g}_{\text {cat }}^{-1} \mathrm{~h}^{-1}\right)\end{array}$ & $\begin{array}{l}\text { Conversion } \\
\text { to DAA (wt.\%) }\end{array}$ \\
\hline HT-CO & $<0.1$ & $<0.1$ \\
Calcined HT & 2.3 & 8 \\
Rehydrated HT & 13 & 21 \\
Rehydrated HT from [14] & 3 & 25 \\
\hline
\end{tabular}




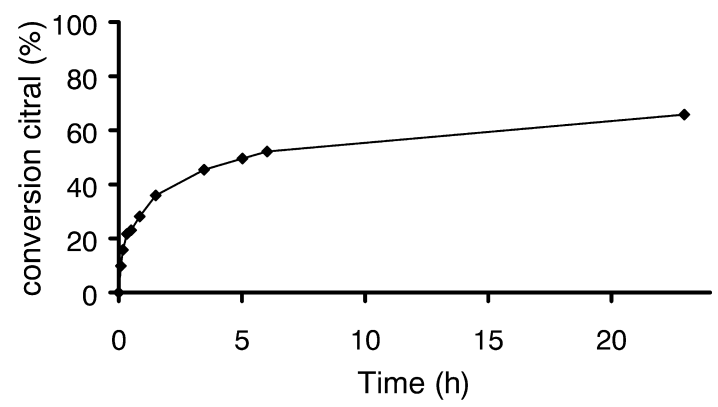

Fig. 6. Conversion of citral at $273 \mathrm{~K}$ with $1 \mathrm{wt}$ \% citral initially present.

[18]). The activity we measured was four times higher than that reported in literature [14] (Table 2).

To suppress self-condensation of citral in the condensation reaction of citral and acetone, a high ratio of acetone/citral was applied. Rao et al. [3] used in the benzaldehyde-acetone condensation a molar acetone/benzaldehyde ratio of 32 and obtained a conversion of $94 \%$ and a selectivity of $86 \%$ to the $\beta$-hydroxy-ketone. We found that with a molar acetone/citral ratio of 20 (corresponding to $10 \mathrm{wt} . \%$ of citral), no reaction took place at all. When the amount of citral was decreased to $1 \mathrm{wt} \%$, both acetone self-condensation and citral-acetone condensation were observed, which demonstrates a strong inhibition by citral at higher concentrations of citral. The reason for this observed inhibition is currently under investigation.

Fig. 6 shows the conversion of citral at $273 \mathrm{~K}$ when a rehydrated HT-catalyst is used. As can be seen, after $24 \mathrm{~h} 65 \%$ of the citral was converted. Furthermore, a selectivity of $90 \%$ was observed. These results show also a sharp decrease of the conversion rate in time. Deactivation could be the reason, since the accompanying self-condensation of acetone is four to five times lowered to yield $5 \mathrm{wt} \%$ DAA after $24 \mathrm{~h}$ (data not shown). Nevertheless, these results show that the modified HT enables the desired citral-acetone condensation to proceed at $273 \mathrm{~K}$. The basic sites appear to be extremely active, resulting in high turn over frequencies (TOFs). The calculated total turn over number (TON) and initial TOF for both performed condensation reactions are presented in Table 3. The calculated numbers for the citral-acetone reaction are low compared with the
Table 3

Total TON and initial TOF for acetone self-condensation and for acetone-citral condensation at $273 \mathrm{~K}$

\begin{tabular}{lrc}
\hline & TON & TOF $\left(\mathrm{h}^{-1}\right)$ \\
\hline DAA production & 2000 & 720 \\
Citral conversion & 35 & 73 \\
\hline
\end{tabular}

acetone self-condensation, due to the low concentration of citral.

\section{Conclusions}

We demonstrated from adsorption measurements that only a small fraction (5\%) of the total number of basic sites in the rehydrated calcined HT-structure is available for liquid-phase aldol condensation reactions at low temperatures. These sites, most likely localized at the edges of HT-platelets, exhibit high catalytic activity in the condensation reactions investigated. Besides a high activity, the rehydrated calcined HTs show a high selectivity. For example, no further condensation products other than DAA in the acetone self-condensation were formed.

Our preliminary results for the citral-acetone condensation show that, even at $273 \mathrm{~K}$, with $1 \mathrm{wt} \%$ citral present, the condensation reaction is catalyzed by modified HTs with reasonable conversions and high selectivities [27]. At $10 \mathrm{wt}$ \% citral no reaction is observed, which points to a negative reaction order in citral. Future experiments will give more insight in the mechanism involved.

\section{Acknowledgements}

The authors wish to thank Prof. Dr. G. van Koten and Dr. J.T.B.T. Jastrzebski for their suggestions in the course of discussions on this subject. Financial support from the Innovation Oriented Research Programmes (IOP Catalysis), an initiative of the Dutch Ministry of Economic Affairs, is gratefully acknowledged.

\section{References}

[1] P. Gradeff, US Patent 3840601 (1975)

[2] W.T. Reichle, J. Catal. 94 (1985) 547.

[3] K.K. Rao, M. Gravelle, J. Valente, F. Figueras, J. Catal. 173 (1998) 115. 
[4] F. Cavani, F. Trifiro, A. Vaccari, Catal. Today 11 (1991) 173.

[5] A. van der Pol, B. Mojet, E. van der Ven, E. de Boer, J. Phys. Chem. 98 (1994) 50.

[6] W. Kagunya, P. Dutta, Z. Lei, Physica B 234 (1997) 910.

[7] W.T. Reichle, J. Catal. 63 (1980) 295.

[8] D. Tichit, M.N. Bennani, F. Figueras, J.R. Ruiz, Langmuir 14 (1998) 2086.

[9] A.L. McKenzie, C.T. Fishel, R.J. Davis, J. Catal. 138 (1992) 547.

[10] M.J. Hudson, S. Carlino, D.C. Apperley, J. Mater. Chem. 5 (1995) 323.

[11] V. Constantino, T. Pinnavaia, Catal. Lett. 23 (1994) 361.

[12] W.T. Reichle, S.Y. Kang, D.S. Everhardt, J. Catal. 101 (1986) 352.

[13] E. Suzuki, Y. Ono, Bull. Chem. Soc. Jpn. 61 (1988) 1008.

[14] R. Teissier, D. Tichit, F. Figueras, J. Kervennal, French Patent 2729137 (1995).

[15] A. Guida, M. Hassane Lhouty, D. Tichit, F. Figueras, P. Geneste, Appl. Catal. 164 (1997) 251.

[16] J.I. Di Cosimo, V.K. Diez, C.R. Apesteguia, Appl. Clay Sci. 13 (1998) 433.
[17] S. Lippert, W. Baumann, K. Thomke, J. Mol. Catal. 69 (1991) 199.

[18] G. Podrebarac, F. Ng, G. Rempel, Chem. Eng. Sci. 52 (1997) 2991.

[19] G. Salvapati, K. Ramanamurty, M. Janardanarao, J. Mol. Catal. 54 (1989) 9.

[20] C. Noda, G.P. Alt, R.M. Werneck, C.A. Henriques, J.L.F. Monteiro, Braz. J. Chem. Eng. 15 (1998) 120.

[21] F. Rey, V. Fornes, J.M. Rojo, J. Chem. Soc., Faraday. Trans. 88 (1992) 2233.

[22] L. Pesic, S. Salipurovic, V. Markovic, D. Vucelic, W. Kagunya, W. Jones, J. Mater. Chem. 2 (1992) 1069.

[23] E. Kanezaki, Inorg. Chem. 37 (37) (1998) 2588.

[24] J.T. Kloprogge, R.L. Frost, Appl. Catal. 184 (1999) 61.

[25] J.T. Kloprogge, R.L. Frost, Phys. Chem. Chem. Phys. 1 (1999) 1641.

[26] G. Zhang, H. Hattori, K. Tanabe, Appl. Catal. 36 (1988) 189.

[27] J.C.A.A. Roelofs, A.J. van Dillen, J.W. Geus, J.T.B.T. Jastrzebski, K.P. de Jong, European Patent Application 99200450.7. 